\title{
An Empirical Study to Understanding Students Continuance Intention Use of Multimedia Online Learning
}

\author{
Taqwa Hariguna ${ }^{1, *}$ \\ ${ }^{1}$ Information System Program College of AMIKOM Purwokerto Central Java, Indonesia \\ ${ }^{1}$ taqwa@amikompurwokerto.ac.id* \\ * corresponding author
}

(Received June 3, 2021 Revised June 13, 2021 Accepted June 25, 2021, Available online July 1, 2021)

\begin{abstract}
The purpose of this study was to assess students' ongoing intentions towards online multimedia learning such as perceived usefulness, ease of use, and flow experience. The sample of this study was 523 students who used off-campus/online learning resources and examined the content of online learning resources and their multimedia aspects. The Extended of Technology Acceptance Model (TAM) was used to predict students' continuing intentions. The results showed that students' intentions were positively influenced by their perceived usefulness, ease of use, and flow experience. It is suggested that the designer of multimedia online learning should be more specific in determining the target users to receive and cultivate a more positive sustainable intention.
\end{abstract}

Keywords: Multimedia online learning; TAM; Continuance intention;

\section{Introduction}

Online learning is one of the new learning paradigms and is becoming the most prospective and growing rapidly today [1-4]. With its rapid growth, online learning providers have produced and designed many competing learning template models such as Moodle, Edmodo, whiteboard system, etc. To proactively achieve learning objectives and design interventions (teacher training, user orientation, student assessment and evaluation, etc.), it is important for designers and managers of online learning to understand how to attract the attention of users who may be less interested in adopting and using online learning systems.

Because students are the end users of the online learning system, learning designers need interesting media to convey the learning content provided by the supervisor or lecturer. Students' attention to the lesson, for example, can be maintained by providing menus and tools for communication channels, discussion forums, message boards, and chat rooms. To be effective and useful for students, the content of the lesson determined by the mentor or lecturer must be interpreted by multimedia specialists in an interesting, economical and communicative way. Thus, multimedia not only serves as a means of communication but also increases student learning motivation, attention and leads to student success [5].

The extent to which a person believes that using a particular system will improve student activity performance is called perceived usefulness [6]. In the past few years, many studies have revealed that perceived usefulness as well as ease of use (the degree to which one believes that using a particular system will be effort-free) are important factors in IT/IS adoption. Perceived usefulness in the TAM model initially refers to work-related productivity, performance, and effectiveness [6]. Moreover, perceived usefulness is an example of an extrinsic motive.

Another finding confirms that there is also an intrinsic motive called flow experience (Flow Theory). [7] It was noted that flow experience was associated with positive subjective experience and exploratory behavior. This state of flow often occurs in the various types of interactions involved in the context of online learning or Internet suffering. 
In addition, the flow of experience, characteristics, and individual experiences of students can also influence online multimedia learning behavior. [8] Considering individual differences as an important factor in consumer acceptance of new information technology products or services.

Referring to the findings of previous studies above, it is necessary to modify and expand TAM by considering individual differences. Assessment of student activity in using online learning multimedia and the proposed TAM [9] are expected to better explain students' intentions to continue using online multimedia learning resources.

\section{Hypotheses and Research Model}

\subsection{Technology acceptance model (TAM)}

Among a number of theoretical models used to explain individual acceptance, adoption, and use of information technology/systems, TAM is the most popular because it can predict user behavior or perceptions, and determines usability and ease of use as key factors. [10-11].

TAM is derived or generated from Theory of Reasoned Action (TRA). According to TAM, IT/IS user adoption is influenced by perceived usefulness and ease of use. Perceived usefulness is defined as the degree to which a person believes that using a particular system will be free of effort.

In relation to the effectiveness of TAM, empirical studies were carried out by several scholars to investigate the relationship between student behavior, multimedia learning content and multimedia learning systems [12-14]. Their findings suggest that congruence between student characteristics and multimedia technology results in greater enjoyment while experiential influences may moderate behavioral effects. Other empirical studies have confirmed that there are several other key factors in the TAM model such as consumer age, gender, and experience [15-17].

It is specifically mentioned that perceived usefulness and perceived ease of use positively affect consumers' intention to use the Internet. This means that the intuitive user interface can make their job easier and therefore do the job more efficiently. Many studies have also shown that perceived ease of use is likely to increase perceived usefulness [18] [15]. This relationship has been further supported by extended TAM [8] [6] [19] [20] [21] [10] [22]. Thus, the following hypothesis is proposed:

H1: Students' perceived ease of use (SPE) has a positive effect on students' continuance intentions (SCI).

H2: Student Perceived usefulness (SPU) has a positive effect on student continuance intention (SCI).

H3: Students' perception of ease of use (SPE) has a positive effect on students' perceptions of usefulness (SPU).

\subsection{Flow Experience}

The concept of flow experience which was first proposed by [23] is used as a benchmark to determine an experience in accessing information systems. The flow of experience, is also a representation of a person's perception and experience of the use of information systems. This will give encouragement to someone involved in the system to limit themselves to every activity that exists. [24] Says that flow experience is developed and can be measured and analyzed so that flow experience affects customer satisfaction and a person's behavior in the future.

In online activities, internet users will get a different experience. This will have the impact that internet users must master their own environment as well to get a good experience [25].

In another study it was explained that comfort and concentration are the two most important factors in the flow experience [26]. In another study [7] explained that the ease of flow of experience is an important positive factor for e-mail users. [25] also showed that the flow experience and perceived comfort for the user have a strong relationship. Therefore, we hypothesize:

H4: Student perceived ease of use (SPE) has a positive effect on student flow experience (SFE). 
In another study, flow experience can be used to analyze and predict a person's sustainability and intention to carry out online activities [25]. Therefore, we hypothesize:

H5: Student flow experience (SFE) has a positive effect on student continuance intention (SCI).

From the above explanation, we synthesize the related constructs and propose a research model to explain and predict students' continuance intention towards online multimedia learning adoption (as shown in Figure 1).

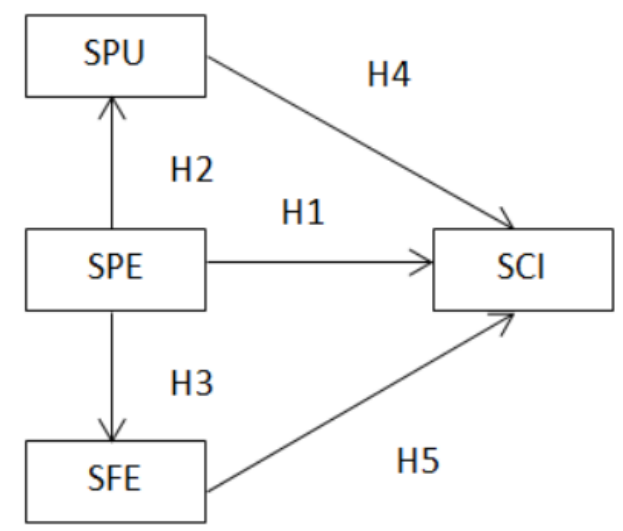

Figures. 1. Hypotheses Development and Research Model

Notes: Student perceived usefulness (SPU), Student perceived ease of use (SPE), Student flow experience (SFE), Student continuing intent (SCI).

\section{Research Method}

\subsection{Instrument Design}

Empirical data were collected through a questionnaire. They are divided into two parts of the user's personal information; age, education, occupation, experience of using multimedia online learning and frequency of use, and theoretical construction of the proposed model to measure user perceptions of continued use of multimedia online learning. A questionnaire with a seven-point Likert scale was distributed to 523 students from January 20, 2016 to April 15, 2016.

The construction and source scale items are: Continue intention: four items adapted from [27] [28]. Ease of use and perceived usefulness: both of the four items were slightly modified from [29] and [30] Experience flow: four items were adopted from [25].

\subsection{Sampling Method}

The research used a purposive sampling method as there were 523 valid samples taken from online learning students. Respondents must have a qualification that has participated or are participating in multimedia online learning to facilitate improved external validity. (as shown in Table 1). 
Tables. 1. Present the Demographics of the Respondents

\begin{tabular}{|c|c|c|}
\hline $\begin{array}{l}\text { Characteristics of the } \\
\text { subjects }\end{array}$ & Number & $\%$ \\
\hline \multicolumn{3}{|l|}{ Gender } \\
\hline Male & 321 & 61.38 \\
\hline Female & 202 & 38.62 \\
\hline \multicolumn{3}{|l|}{ Age } \\
\hline Under 20 years & 120 & 22.94 \\
\hline $20-25$ years of age & 300 & 57.36 \\
\hline $27-33$ years old & 103 & 19.69 \\
\hline \multicolumn{3}{|l|}{ Education } \\
\hline High school & 120 & 22.94 \\
\hline Under graduate students & 300 & 57.36 \\
\hline Graduate students & 103 & 19.69 \\
\hline \multicolumn{3}{|l|}{ Experiences } \\
\hline 6 Months & 120 & 22.94 \\
\hline 1 Year & 300 & 57.36 \\
\hline More than 1 year & 103 & 19.69 \\
\hline
\end{tabular}

\section{Results}

\subsection{Outer model}

In PLS, the relationship between indicators and latent constructs is referred to as the outer model [31]. To test the reliability of each existing construction (construct item) required Cronbach and composite reliability with a construction value of 0.7 or more, which means that the existing construction is acceptable and reliable. Table 2 shows that Factor Loads and reliability tests are in accordance with predetermined indicators. To test the construct validity, in this study two methods were used, namely the convergent validity test and the discriminant validity test. As the theory put forward by [32] which states that a construction can be declared convergent validity if the load factor value on each indicator has a value greater than 0.5 , and the average extracted variance (AVE) value is greater than 0.5 , and the composite reliability value is greater than 0.7 . Table 2 shows that all constructs are in accordance with the theory proposed by [32].

Furthermore, to test the discriminant validity, the formula is used that the square root of the AVE must be greater than the correlation coefficient of the construction [33]. In Table 3 and Table 4, each of the existing constructs is in accordance with the validity test criteria. 
Table. 2. Reliability Analysis and Convergent Validity

\begin{tabular}{|c|c|c|c|c|c|}
\hline Construct & $\begin{array}{l}\text { Measurement } \\
\text { item }\end{array}$ & $\begin{array}{c}\text { Factor } \\
\text { loading/coefficient }\end{array}$ & $\begin{array}{l}\text { Cranach's } \\
\text { Alpha }\end{array}$ & AVE & $\begin{array}{l}\text { Composite } \\
\text { Reliability }\end{array}$ \\
\hline \multirow{5}{*}{ SCI } & SCI1 & 0.860 & \multirow{5}{*}{0.922} & \multirow{5}{*}{0.762} & \multirow{5}{*}{0.941} \\
\hline & SCI2 & 0.862 & & & \\
\hline & SCI3 & 0.932 & & & \\
\hline & SCI4 & 0.821 & & & \\
\hline & SCI5 & 0.887 & & & \\
\hline \multirow{5}{*}{ SFE } & SFE1 & 0.862 & \multirow{5}{*}{0.917} & \multirow{5}{*}{0.750} & \multirow{5}{*}{0.938} \\
\hline & SFE2 & 0.854 & & & \\
\hline & SFE3 & 0.825 & & & \\
\hline & SFE4 & 0.904 & & & \\
\hline & SFE5 & 0.884 & & & \\
\hline \multirow{5}{*}{ SPE } & SPE1 & 0.886 & \multirow{5}{*}{0.945} & \multirow{5}{*}{0.819} & \multirow{5}{*}{0.958} \\
\hline & SPE2 & 0.920 & & & \\
\hline & SPE3 & 0.913 & & & \\
\hline & SPE4 & 0.876 & & & \\
\hline & SPE5 & 0.930 & & & \\
\hline \multirow{5}{*}{ SPU } & SPU1 & 0.863 & \multirow{5}{*}{0.915} & \multirow{5}{*}{0.746} & \multirow{5}{*}{0.936} \\
\hline & SPU2 & 0.848 & & & \\
\hline & SPU3 & 0.820 & & & \\
\hline & SPU4 & 0.903 & & & \\
\hline & SPU5 & 0.882 & & & \\
\hline
\end{tabular}

Notes: Student perceived usefulness (SPU), Student perceived ease of use (SPE), Student flow experience (SFE), Student continuing intent (SCI).

Tables. 3. Correlation Matrix

\begin{tabular}{|c|c|c|c|c|}
\hline & SCI & SFE & SPE & SPU \\
\hline SCI & 0.873 & & & \\
\hline SFE & 0.813 & 0.866 & & \\
\hline SPE & 0.805 & 0.877 & 0.905 & \\
\hline SPU & 0.812 & 0.807 & 0.816 & 0.864 \\
\hline
\end{tabular}

Note: Student perceived usefulness (SPU), Student perceived ease of use (SPE), Student flow experience (SFE) Student continues intention (SCI).

\subsection{Common method variance testing}

In each study using the questionnaire survey method, the main problem found by researchers is the problem of common method variance (CMV). This happened because some people who responded to the questionnaire were less serious. Based on suggestions [34], in this study we designed a questionnaire that had gone through a rigorous process, where we designed a questionnaire based on the advice of experts in the field of information systems and learning systems, then we used journal references that had good credibility, and the last one was pre-test. -test to modify the semantics of the questionnaire. In addition to the Harman single factor test, we used the CMV presence test [35]. The basic assumption of the Harman single factor test is that CMV is confirmed when one factor can explain most of the covariance of the variables present. From the test results, it is known that these factors fail to explain $50 \%$ of the existing variance, meaning that the existing questionnaire does not indicate the presence of CMV. 


\subsection{Inner Model}

Determining the structure of the path between the PLS is called inner construction model. To examine the results of the significance of hypotheses, the reference value used is the t-value, and the results of hypothesis can be seen in Table 3 and Figure 2. From these displays, five hypotheses formulated in the research were answered.

Tables. 4. Summary of Hypothesis Testing Results

\begin{tabular}{|l|l|l|l|l|}
\hline Hypothesis & Path & $\begin{array}{l}\text { Standardized path } \\
\text { coefficient }\end{array}$ & t-value & Supported \\
\hline H1 & SPE -> SCI & $0.447^{* * *}$ & 4.520 & Yes \\
\hline H2 & SPE -> SPU & $0.868^{* * *}$ & 13.279 & Yes \\
\hline H3 & SPE -> SFE & $0.765^{* * *}$ & 11.398 & Yes \\
\hline H4 & SPU -> SCI & $0.509^{* * *}$ & 1.260 & Yes \\
\hline H5 & SFE -> SCI & $0.607^{* * *}$ & 1.811 & Yes \\
\hline
\end{tabular}

Note1: ${ }^{* *}$-value $<0.01 ; * *$ p-value $<0.001$

Note2: Student perceived usefulness (SPU), Student perceived ease of use (SPE), Student flow experience (SFE), Student continued intent (SCI).

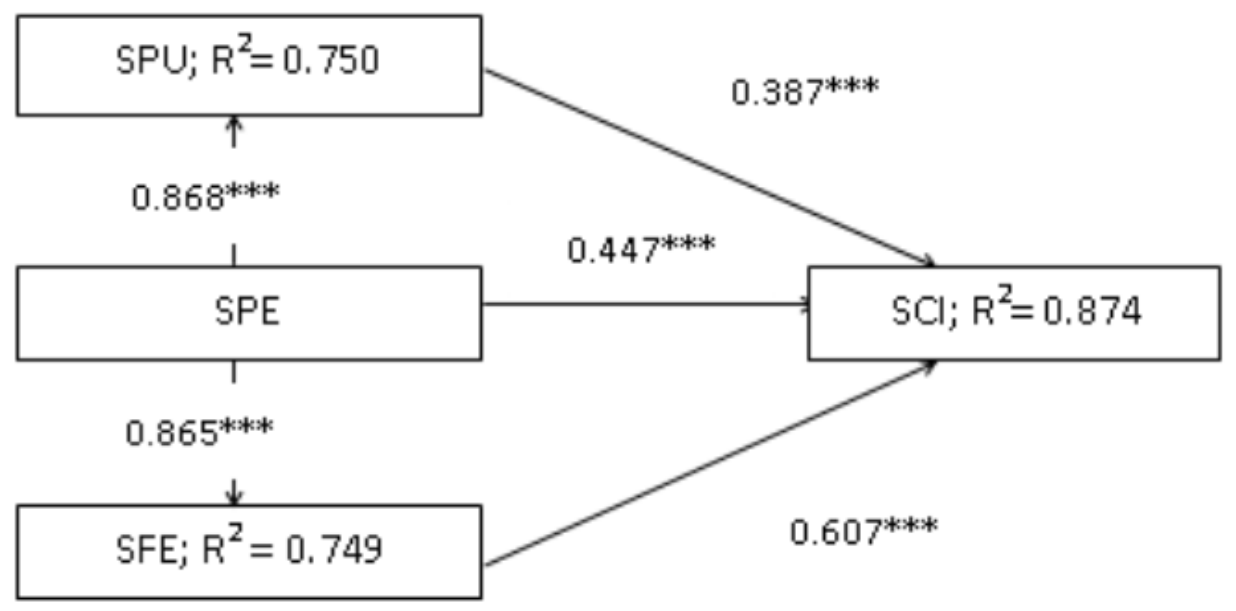

Figures. 2. Inner Model and Path Coefficient

Note1: $* *$ p-value $<0.01 ; * *$ p-value $<0.001$

Note2: Student perceived usefulness (SPU), Student perceived ease of use (SPE), Student flow experience (SFE), Student continuing intent (SCI).

\subsection{Mediating effects}

Path analysis only shows the direct effect of the variables. To assess indirect or mediating effects, the four pathways shown in Table 5 were tested using the Sobel Test, Aroian Test and Goodman Test. The test results in Table 5 are all significant, indicating that student flow experience (SFE) and student perceived usefulness (SPU) mediate the effects of other variables as expected. 
Tables. 5. Mediation Effects Testing

\begin{tabular}{|c|c|c|c|c|c|}
\hline Constructs & $\begin{array}{l}\text { Construct } \\
\text { relationships }\end{array}$ & $\begin{array}{l}\text { T-value of path } \\
\text { coefficients }\end{array}$ & $\begin{array}{l}\text { Sobel test's } \\
\text { z-value }\end{array}$ & $\begin{array}{l}\text { Aroian } \\
\text { test }\end{array}$ & $\begin{array}{l}\text { Goodman } \\
\text { test }\end{array}$ \\
\hline \multirow{2}{*}{ SPE-SPU-SCI } & SPE -> SPU & 13.279 & \multirow{2}{*}{$1.254 * *$} & \multirow{2}{*}{$1.251 * *$} & \multirow{2}{*}{$1.258 * *$} \\
\hline & SPU $>>$ SCI & 1.260 & & & \\
\hline \multirow{2}{*}{ SPE-SFE-SCI } & SPE -> SFE & 11.398 & \multirow{2}{*}{$1.789 * *$} & \multirow{2}{*}{$1.782 * *$} & \multirow{2}{*}{$1.795 * *$} \\
\hline & SFE -> SCI & 1.811 & & & \\
\hline
\end{tabular}

Note1: ${ }^{* *}$ p-value $<0.01 ; * * *$ p-value $<0.001$

Note2: Student perceived usefulness (SPU), Student perceived ease of use (SPE), Student flow experience (SFE), Student continuing intent (SCI).

\section{Discussion, Conclusion and Future Works}

\subsection{Discussion}

Effects of students' perceived ease of use on students' continuation intentions (H1)

The results showed that students' perceived ease of use (SPE) had a significant effect on students' continuing intentions towards online multimedia learning (SCI). [16] It was found that perceived ease of use is an important factor in the early stages of system use. The importance of ease of use can affect students' understanding of web content. As a result, students will increase motivation for learning activities.

The effect of students' perceived usefulness on sustained intention (H2)

The results showed that the benefits felt by students directly influenced students' intention to continue. This is in line with the findings mentioned by [10] and [22] that perceived usefulness is more important than perceived ease of use in predicting acceptance of new technologies. To improve the usefulness of online learning multimedia, it is important that online learning providers have an accurate understanding of user needs and design appropriate multimedia content.

The effect of students' perceived ease of use on perceived usefulness (H3)

This study has confirmed that students' perceived ease of use has a positive effect on students' perceived usefulness, consistent with the findings of most studies of the extended TAM model. The ease of use of students also has a direct effect on students' intentions to continue online multimedia learning. This finding is consistent with previous research on hedonic information systems [20]. Therefore, online learning providers are advised to design multimedia interfaces, content and interactions that are very easy to use and follow, especially for new students.

Effects of student perceived ease of use on flow experience (H4)

From the analysis it is explained that the ease of use felt by students has a positive effect on the experience of student flow. In other words, online learning multimedia that can be used easily has an impact on students in controlling their activities quickly and easily and for learning. This is part of the flow experience. Student flow experience is a theory that describes the relationship between human activities and computers, which is a process in which a person explores information systems in detail. This experience will have an impact on one's satisfaction and one's feelings to carry out further exploration of information systems [25].

The importance of students' perceived ease of use has been discussed previously through its indirect effect on students' perceived usefulness. This has a similar indirect effect through flow experiences as discussed below. 
The effect of students' flow experience on students' continuation intentions (H5)

From our research we conclude that the experience of student flow has a positive effect on the continuing intention of online multimedia learning. In a previous study [7] suggested that flow experience is a feeling that arises from human-computer interaction. During this period students will learn and interact through online multimedia systems, this will result in new experiences for students. Therefore, the experience of student flow has a direct impact on students' behavior towards multimedia online learning and also determines the intention to continue using. In another study [25] identified that flow experience has been an important predictor of online systems.

\subsection{Conclusion}

It is very important to understand the factors that determine students' continuing intention in online multimedia learning. This study has found that positive student perceived benefits, student ease of use and student flow experience all have positive effects on students' continuance intentions. The larger the indicators correspond to the higher the intention to sustain. This study found a positive effect on students' perceived usefulness, and students' perceived ease of use on students' flow experiences. Significant results of student perceived benefit and student flow experience were obtained in most of the relationships as expected. Significant results were found in all relationships as expected. Since the researcher used an online questionnaire, there may be some bias in the answers given by students who do not use multimedia content often.

\section{References}

[1] Chang, W., Wu, Y., \& Yang, J. (2011). LNCS 6872 - Web and Video-Based Summary Learning Platform for Online Multimedia Learning, 355-362.

[2] Zhao, Z., Ali Etemad, S., \& Arya, A. (2016). Advances in Intelligent Systems and Computing. Proceedings of the 10th International Symposium on Computer Science in Sports (ISCSS), 392 (August), 233-240.

[3] Wang, C. Y., Tsai, M. J., \& Tsai, C. C. (2016). Multimedia recipe reading: Predict learning outcomes and diagnose cooking interest using eye tracking measures. Computers in Human Behavior, 62, 9-18.

[4] Yousafzai, A., Chang, V., Gani, A., \& Noor, R. M. (2016). Multimedia augmented m-learning: Issues, trends and open challenges. International Journal of Information Management, 36(5), 784-792.

[5] Schweppe, J., \& Rummer, R. (2016). Integrating written text and graphics as desired difficulty in long-term multimedia learning. Computers in Human Behavior, 60, 131-137.

[6] Davis, F. (1989) 'Perceived usefulness, perceived ease of use, and user acceptance of information technology'. Quarterly MIS, 13(3), 319-340.

[7] Trevino, L.K.; Webster, J.; Ryan, L. (1993) Dimensions and Correlation of Flows in Human-Computer Interaction. Computers in Human Behavior, 9(4), Winter, 411-426.

[8] Agarwal, R., \& Prasad, J. (1999). Are individual differences closely related to the acceptance of new information technology? Decision Science, 30(2), 361-391.

[9] Parasuraman, A. (2000). Technology Readiness Index (TRI): A multi-item scale to measure readiness to accept new technology. Journal of Service Research, 2(4), 307-320.

[10] Venkatesh, V. (2000). Perceived ease of use determinants: Integrating control, intrinsic motivation, and emotion into the technology acceptance model. Information Systems Research. 11, 342-365.

[11] Hariguna, T., Lai, MT., and Chen, SC., (2017). "Understanding the quality of information systems on public e-government service intentions: an empirical study". Int. J. Innovation and Sustainable Development, 11(2/3), 271-290. 
[12] Altas, B. (2015). Knowledge Construction in Multimedia Learning at the Cognitive and Affective Level. Procedia - Social and Behavioral Sciences, 191, 1448-1454.

[13] Amadieu, F., Wardrobe, J., \& Tricot, A. (2013). How do multimedia and hypertext documents support deep processing for learning? Psychology Francaise.

[14] Angeli, C., \& Tsaggari, A. (2016). Examining the effects of dyadic learning with computer-based multimedia on the performance of third graders in history. Computers and Education, 92-93, 171-180.

[15] Venkatesh, V., \& Davis, F. D. (2000). Theoretical extension of the technology acceptance model: Four longitudinal field studies. Management Science, 45(2), 186-204.

[16] Venkatesh, V., Morris, M. G., Davis, GB, \& Davis, F. D. (2003). Information technology user acceptance: Towards a unified view. MIS Quarterly, 27(3), 425-478.

[17] Teo, T. S. H., Lim, V. K. G., \& Lai, R. Y. C. (1999). Intrinsic and extrinsic motivation in internet use. Omega, $27,25-37$.

[18] Taylor, S., Todd, PA, (1995). Understanding the use of information technology: testing competing models. Information Systems Research 6 (2), 144-176.

[19] Davis, F.D., Bagozzi, R.P. and Warshaus, PR (1989). "User acceptance of computer technology: a comparison of two theoretical models". Management Science, 35(8), 982-1003.

[20] Van der Heijden, H., (2003). Factors influencing website use: the case of generic portals in the Netherlands. Information \& Management, 40 (6), 541-549.

[21] Venkatesh, V., \& Davis, F. D. (1996). Model development and testing of perceived ease of use. Decision Science, 27(3), $451-481$.

[22] Wixom, B. and Todd, P. (2005), “A theoretical integration of user satisfaction and technology acceptance”. Information Systems Research, 16(1), 86-102.

[23] Hoffman, D. L., \& Novak, T. P. (1996). Marketing in a hypermedia computer-mediated environment; conceptual foundation. Journal of Marketing, 60 (July), 50-68.

[24] Csikszentmihalyi, M. (2004). Materialism and the evolution of consciousness, In: T. Kasser \& A. D. Kanner (Eds.), Consumer psychology and culture: The struggle for a good life in a materialistic world (pp. 91-106). Washington, DC: American Psychological Association.

[25]Hsu, C.; Lu, H. (2004) Why do people play online games? Extended TAM with social influences and flowing experiences. Information and Management, 41, 853-868.

[26] Ghani, JA, Supnick, R. and Rooney, P. (1991), 'The experience of flow in computer mediated and in face to face groups', in Degross, JI, Benbasat, I., Desantis, G. and Beatj, CM (eds), New York, NY, 229-37.

[27] Bhattacherjee, A., (2001a). Understanding information systems continuance: an expectation-confirmation model. MIS Quarterly, 25(3), 321-370.

[28] Bhattacherjee, A., (2001b). An empirical analysis of the antecedents of electronic commerce service continuance. Decision Support Systems, 32(2), 201-214.

[29] Pavlou, P. (2003). Consumer acceptance of electronic commerce: Integrating trust and risk with the technology acceptance model. International Journal of Electronic Commerce, 7, 101-134.

[30] Chen, S.-C., Chen, H.-H., \& Chen, M.-F. (2009). Determinants of satisfaction and continuance intention towards self-service technologies. Industrial Management \& Data Systems, 109, 1248-1263. 
[31] Hariguna, T., Lai, MT., \& Chen, SC., “An Empirical Study on the Impact of Information System Quality on Software as a Service”, Global Business and Management Research: An International Journal, 8(3), 43 -54, 2016.

[32]Fornell, C., \& Larcker, D. F. (1981). Evaluating structural equation models with unobservable variables and measurement error. Journal of Marketing Research, 18(1), 39-50.

[33] Hariguna, T., \& Berlinana (2017). Understanding of Antecedents to Achieve Customer Trust and Customer Intention to Purchase E-Commerce in Social Media, an Empirical Assessment, 7(3), 1240-1245.

[34] Podsakoff, P. M., MacKenzie, S. B., Lee, J.-Y., \& Podsakoff, N. P. (2003). Common method biases in behavioral research: a critical review of the literature and recommended remedies. The Journal of Applied Psychology, 88(5), 879-903.

[35] Podsakoff, P. M., \& Organ, D. W. (1986). Self-reports in organizational research: Problems and prospects. Journal of Management, 12, 69-82. 